\title{
PENENTUAN HARGA POKOK PRODUKSI BATIK TULIS MENGGUNAKAN ACTIVITY BASED COSTING (ABC) : STUDI KASUS DI BATIK TOBAL PEKALONGAN
}

\author{
Jilma Dewi Ayu Ningtyas ${ }^{1 *}$, Bayu Wirawan D. S. ${ }^{2}$ \\ ${ }^{1}$ Program Studi Akuntansi, Politeknik Pusmanu Pekalongan \\ ${ }^{2}$ Program Studi Teknik Batik, Politeknik Pusmanu Pekalongan \\ Jalan Raya Karangdowo No.9 Kedungwuni Pekalongan
}

Korespondensi: jilmadewi@gmail.com ${ }^{1 *}$ bayuwirawands@politeknikpusmanu.ac.id

\begin{abstract}
The purpose of this study is to produce a calculation of the cost of batik production based on activity based costing. The object of research is the cost of production cost in making batik in Tobal Batik in Pekalongan. For the subject of this study were written batik products from Batik Tobal Pekalongan business which is located at Jl. Teratai No. 24, Klego, Pekalongan Timur, Pekalongan City, Central Java. This type of research is qualitative by studying more in calculations with the activity based costing system in determining the cost of production in the business of Tobal batik. Data collection method uses observation, interview and documentation techniques. The data analysis method uses descriptive analysis by using the two-stage activity based costing system based on this research. It can be concluded that the determination of the cost of batik production in Batik Tobal by calculating the activity based costing system is Rp. 25,695,667, for the number of units produced 100 meters so the cost of producing batik per meter is IDR 256,957.
\end{abstract}

Keywords: Cost of production, Written batik, Activity based costing system

\section{PENDAHULUAN}

Perubahan lingkungan perusahaan manufaktur pada saat ini adalah adanya teknologi yang semakin maju, pendeknya daur hidup produk, meningkatnya kerumitan produksi, peningkatan intensitas modal, meningkatnya jalur distribusi dan kualitas produk, banyaknya produk dan meningkatnya diversifikasi produk. Adanya lingkungan yang berubah tersebut mengakibatkan proses produksi juga berubah. Perusahaan berusaha berusaha mengefisienkan proses produksinya agar dapat bersaing. Persaingan global tidak hanya menuntut perusahaan untuk memproduksi barang dalam jumlah banyak akan tetapi bagaimana produsen tepat dalam perhitungan harga produksinya karena apabila harga barang produksi terlalu mahal kemungkinan produk tidak diminati konsumen, sebaliknya apabila terlalu rendah dapat menyebabkan biaya yang sangat besar.

Pada lingkungan industri yang fluktuatif, pembebanan BOP (Biaya Overhead Pabrik) berdasarkan pada Biaya Tenaga Kerja Langsung (BTKL) akan menghasilkan pembebanan BOP yang tidak akurat karena BTKL tidak menunjukkan hubungan sebab akibat antara output dengan BOP. Dasar penetapan BOP yang lebih representatif adalah dengan menerapkan activity based costing ( $\mathrm{ABC}$ ) yaitu perhitungan Harga Pokok Produk berdasarkan aktivitas. ABC dikenal juga dengan transaction costing (pembebanan Harga Pokok Produk berdasarkan transaksi). Aktivitas (transaksi) yang mengkonsumsi sumber daya overhead, diidentifikasikan dan dihubungkan dengan biaya (BOP) yang terjadi. Anggapan dasar pada activity based costing adalah BOP yang disebabkan oleh aktivitas dapat diusut ke unit produk individual berdasarkan frekuensi pemakaian sumber daya overhead oleh setiap produk (Daljono, 2009). 
Menurut Sujarweni (2015) biasanya banyak peneliti melakukan penelitian tentang perbandingan antara metode konvensional full costing dan variabel costing atau metode tradisional yaitu metode yang sudah digunakan perusahaan selama ini untuk menghitung harga pokok produksinya dibandingkan dengan jika harga pokok produksinya dihitung berdasarkan activity based costing. Metode konvensional menitikberatkan penentuan harga pokok pada fase produksi saja, sedangkan activity based costing menitikberatkan penentuan harga pokok produk pada semua fase pembuatan produk yaitu (1) fase desain dan pengembangan produk (2) fase produksi (3) fase dukungan logistic.

\section{RUMUSAN MASALAH}

Usaha batik adalah usaha yang memproduksi output berupa batik. Usaha batik memproduksi berbagai macam jenis batik, batasan penelitian ini hanya membatasi produk batik tulis. Menurut fakta permasalahan yang terjadi di lapangan usaha Batik Pekalongan masih menggunakan sistem konvensional atau full costing di mana penentuan harga pokok produksi dengan cara mengumpulkan semua pengeluaran yang telah dikeluarkan selama proses produksi berlangsung kemudian membaginya ke jumlah output yang dihasilkan memiliki harga yang relevan dan baik untuk konsumen dan produsen, padahal sistem biaya konvensional kurang akurat digunakan untuk menghitung harga pokok produksi. Tujuan penelitian ini adalah menghasilkan perhitungan harga pokok produksi batik tulis berdasarkan activity based costing.

\section{TINJAUAN PUSTAKA}

\subsection{Biaya Berdasarkan Pengelompokan Biaya}

3.1.1. Biaya pabrik/manufaktur

- Biaya bahan baku

Biaya yang dikeluarkan untuk membeli bahan baku utama yang dipakai untuk memproduksi barang. Contohnya pembelian kain untuk membuat batik

- Biaya tenaga kerja langsung

Biaya yang dikeluarkan untuk membayar tenaga kerja utama yang langsung berhubungan dengan produk yang diproduksi dari bahan baku mentah menjadi barang jadi. Contohnya biaya untuk membayar pegawai yang langsung membuat batik.

- Biaya overhead pabrik

Biaya yang dikeluarkan untuk memproduksi barang, selain biaya bahan baku dan biaya tenaga kerja langsung. : (a) biaya bahan tidak langsung adalah biaya yang dikeluarkan untuk membeli bahan yang dibutuhkan untuk menyelesaikan suatu produk, namun pemakaiannya sedikit. Contohnya : biaya pembelian benang (b) biaya tenaga kerja tidak langsung adalah biaya yang dikeluarkan untuk membayar gaji tenaga kerja namun tenaga kerja tersebut secara tidak langsung mempengaruhi pembuatan barang jadi. Contoh biaya gaji pengawas produksi.(c) biaya tidak langsung lainya yaitu biaya yang dikeluarkan untuk memproduksi barang yang secara tidak langsung berkaitan dengan produksi barangnya. Contoh biaya telepon untuk memesan bahan baku, listrik untuk menghidupkan mesin. 


\subsubsection{Biaya komersial}

- Biaya Pemasaran

Biaya-biaya yang dikeluarkan untuk keperluan melakukan kegiatan pemasaran atau promosi produk. Contohnya adalah biaya iklan, biaya pengiriman barang.

- Biaya Administrasi

Biaya-biaya yang dikeluarkan untuk mengkoordinasi dan mengendalikan kegiatan produksi dan pemasaran produk. Contoh biaya gaji bagian akuntansi, personalia, keuangan.

\subsection{Konsep Dasar Sistem Activity Base Costing}

Metode ABC (Activity Based Costing) adalah sistem akumulasi biaya dan pembebanan biaya produk dengan menggunakan berbagai cost driver, dilakukan dengan menelusuri biaya dari aktivitas dan setelah itu menelusuri biaya dari aktivitas ke produk. Mengidentifikasi biaya aktivitas dan kemudian ke produk merupakan langkah dalam menyusun activity based costing system (Hansen \& Mowen, 2012).

Activity based costing menurut Garrison dan Noreen (2000) merupakan metode costing yang dirancang untuk menyediakan informasi biaya bagi manajer untuk pembuatan keputusan stratejik dan keputusan lain yang mempengaruhi kapasitas dan biaya tetap. Menurut Mulyadi (2009) activity based costing adalah sistem informasi yang berorientasi pada penyediaan informasi lengkap tentang aktivitas untuk memungkinkan perusahaan melakukan pengelolaan terhadap aktivitas. Tujuan Activity based costing untuk mengalokasikan biaya-biaya produksi berdasarkan aktivitas yang dilaksanakan, kemudian mengalokasikan biaya tersebut berdasarkan aktivitasnya.

\section{METODE PENELITIAN}

\subsection{Sumber Data}

Objek penelitian adalah biaya harga pokok produksi dalam pembuatan batik tulis pada Batik Tobal di Pekalongan. Untuk subjek penelitian ini adalah produk batik tulis dari usaha Batik Tobal Pekalongan yang beralamat di Jl. Teratai No.24, Klego, Pekalongan Timur, Kota Pekalongan, Jawa Tengah.

Jenis penelitian ini adalah penelitia kualitatif deskriptif dengan mengkaji lebih dalam perhitungan dengan sistem activity based costing dalam menentukan harga pokok produksi pada usaha kerajinan Batik Tobal.

Variabel pada penelitian ini adalah biaya dari aktivitas pembuatan batik tulis.

- Biaya bahan baku

- Biaya tenaga kerja

- Biaya overhead pabrik

Metode Pengumpulan data menggunakan teknik Observasi, wawancara dan dokumentasi. Metode analisis data menggunakan analisis deskriptif dengan menggunakan sistem activity based costing dengan dua tahap.

\subsection{Kerangka Pemikiran}

Dalam menentukan harga pokok produksi ada 3 cara yaitu dengan metode full costing, variabel costing dan activity based costing dengan perhitungan untuk memproduski semua produk kemudian dibagi dengan jumlah output yang dihasilkan. 
Metode full costing dan variabel costing ini memiliki keakuratan dan ketepatan menghitung harga pokok produksi namun hanya untuk memproduksi satu jenis barang saja atau homogen, sedangkan activity based costing dalam perhitungan harga pokok produksi yang memproduksi output lebih dari satu jenis lebih tepat dan akurat digunakan, karena merupakan satu-satunya sistem biaya yang menghitung biaya berdasarkan aktivitas satu persatu.

Salah satu produksi dari industri batik di Pekalongan adalah batik tulis, bahan baku yang digunakan adalah kain mori. Tenaga kerja yang ada berjumlah 18 orang. Untuk biaya overhead pabrik yang dibebankan pada produksi batik antara lain biaya penolong, biaya listrik, biaya malam, biaya bahan bakar, dan biaya perawatan peralatan. Dalam mengidentifikasikan biaya overhead tidak dapat dibebankan secara merata atau sama pada semua produk yang dihasilkan karena setiap produk mengkonsumsi biaya overhead yang berbeda-beda sesuai dengan aktivitas produksinya. Identifikasi aktivitas pada biaya overhead pabrik meliputi aktivitas pembuatan pola/pengecapan, aktivitas pewarnaan dan pencucian, aktivitas quisi 1, dan aktivitas pemeliharaan yang masing-masing menimbulkan biaya dari setiap aktivitas produksi yang dilakukan sehingga tempat antara pembebanan biaya kepada tiap jenis hasil produksi sehingga tidak menimbulkan distorsi. Proses perhitungan harga pokok produksi dengan menggunakan system activity based costing terdapat pada kerangka berfikir:

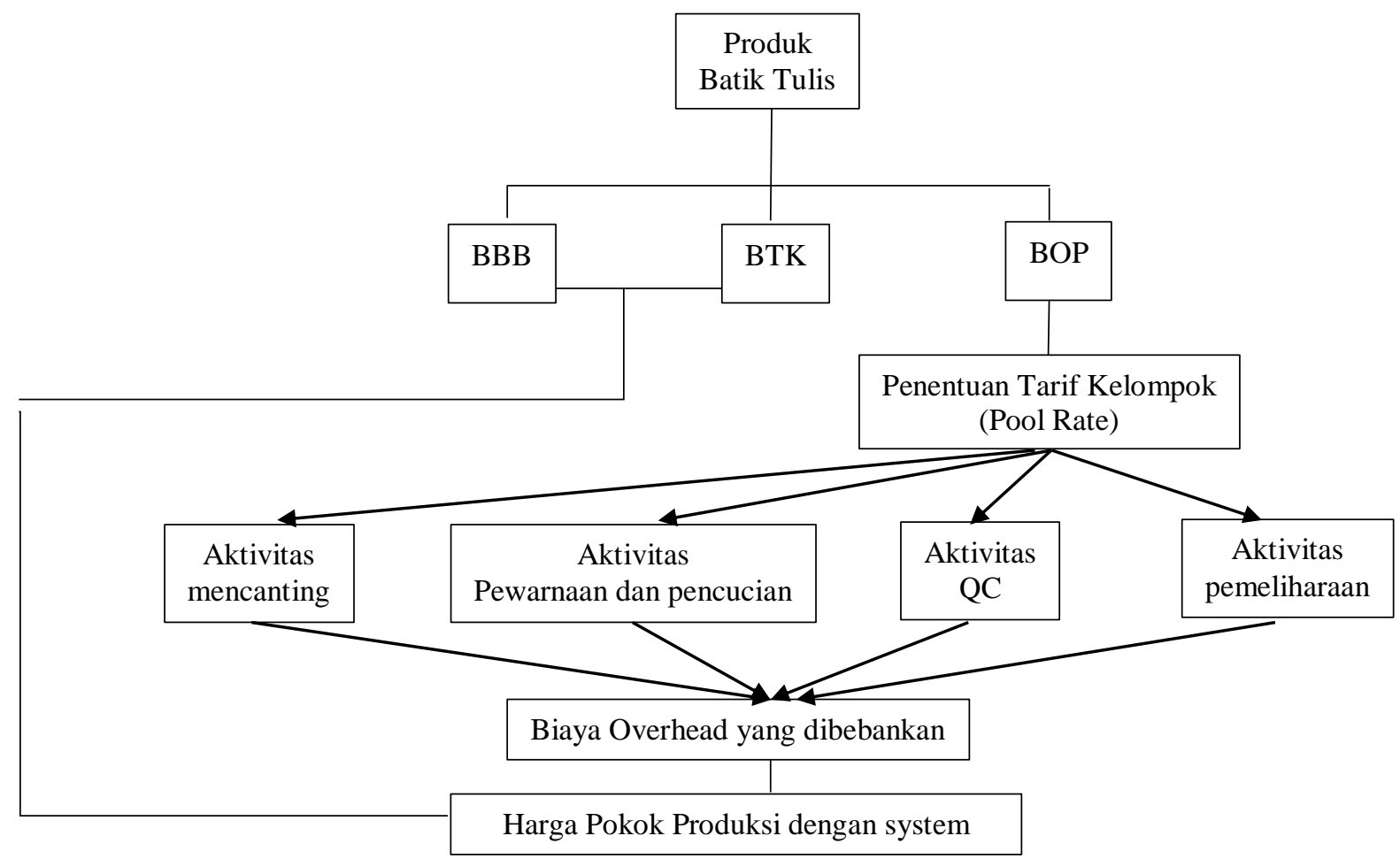

Gambar 1. Kerangka Pemikiran Penelitian

\section{PEMBAHASAN}

\section{Penentuan Harga Pokok Produksi dengan Sistem Activity Based Costing (ABC) pada Produk Batik Tulis}

Penentuan harga pokok produksi yang lebih akurat dapat dilakukan dengan menggunakan sistem activity based costing (ABC). Perhitungan harga pokok produksi 
batik pada usaha batik Tobal dengan sistem ABC menggunakan cost pool batik tulis. Aktivitas yang terjadi dalam pembuatan batik dikelompokkan menjadi 4 cost driver yaitu aktivitas pembuatan pola/ pencantingan, mewarnai dan mencuci, quality control (QC) serta pemeliharaan. Harga pokok produksi dibagi menjadi tiga unsur utama dari biaya yaitu biaya bahan baku (BBB), Biaya tenaga kerja (BTK) dan biaya overhead pabrik (BOP). Sedangkan biaya komersil yaitu biaya-biaya pemasaran.

\subsection{Biaya Bahan Baku}

Bahan baku yang digunakan pada pembuatan batik tulis selama bulan Juli 2018 pada usaha batik Tobal dapat dilihat pada tabel 4.1

Tabel 1. Biaya Bahan Baku

\begin{tabular}{c|c|c|c} 
Bahan Baku & $\begin{array}{c}\text { Jumlah } \\
\text { Pembelian }\end{array}$ & $\begin{array}{c}\text { Harga Bahan Baku } \\
\text { per meter (Rp) }\end{array}$ & $\begin{array}{c}\text { Jumlah Biaya } \\
\text { Bahan Baku (Rp) }\end{array}$ \\
\hline Kain Mori & 100 meter & Rp. 22.000,- & Rp. 2.200.000,-
\end{tabular}

Sumber : Data Batik Tobal bulan Juli 2018

Harga permeter kain mori berbeda-beda tergantung dari kualitas, Batik Tobal menggunakan kain mori dengan harga Rp 22.000,- dan jumlah pembelian perbulan mencapai 100 meter sehingga total biaya bahan baku yang dikeluarkan sebesar Rp 2.200.000,-

\subsection{Biaya Tenaga Kerja}

Biaya tenaga kerja langsung pada usaha Batik Tobal berjumlah 17 pekerja untuk produksi batik tulis. Tenaga kerja dibagi pada setiap bidangnya. Berikut tabel biaya tenaga kerja langsung.

Tabel 2. Biaya Tenaga Kerja Langsung

\begin{tabular}{c|c|c|r} 
Bagian & $\begin{array}{c}\text { Jumlah } \\
\text { Tenaga Kerja }\end{array}$ & $\begin{array}{c}\text { Upah per bulan } \\
(\mathrm{Rp})\end{array}$ & $\begin{array}{c}\text { Jumlah Biaya } \\
\text { Tenaga Kerja (Rp) }\end{array}$ \\
\hline Mencanting & 11 & Rp. $1.000 .000,-$ & Rp. $11.000 .000,-$ \\
\hline Mewarnai dan mencuci & 5 & Rp. $1.300 .000,-$ & Rp. $6.500 .000,-$ \\
\hline QC & 1 & Rp. $1.300 .000,-$ & Rp. $1.300 .000,-$ \\
\hline Total & 17 & & Rp. $18.800 .000,-$
\end{tabular}

\subsection{Biaya Overhead Pabrik}

Biaya overhead pabrik adalah biaya yang langsung mempengaruhi penentuan harga pokok produksi. Biaya ini terjadi karena aktivitas yang dilakukan dalam memproduksi batik tulis.

Penentuan harga pokok produksi batik tulis dengan menggunakan sistem activity based costing menggunakan dua tahap (Sujarweni, 2015)

\subsubsection{Tahap Pertama}

1) Penggolongan berbagai aktivitas

Aktivitas yang terjadi pada proses produksi batik tulis sebagai berikut :

- Aktivitas mencanting

- Aktivitas pewarnaan dan pencucian

- Aktivitas quality control (QC)

- Aktivitas pemeliharaan 
2) Pengasosiasian berbagai biaya dengan berbagai aktivitas

- Aktivitas mencanting

Biaya yang termasuk dalam kelompok aktivitas mencanting adalah biaya malam, biaya gas.

- Aktivitas pewarnaan

Biaya yang termasuk dalam kelompok aktivitas pewarnaan adalah biaya pewarnaan.

- Aktivitas Pemeliharaan

Biaya yang termasuk dalam kelompok aktivitas pemeliharaan adalah biaya pemeliharaan peralatan.

3) Menentukan cost driver yang tepat

Pada penelitian ini cost driver yang digunakan adalah

- Jam tenaga kerja langsung

- Jumlah bahan baku yang digunakan

- Jumlah unit batik yang di produksi

4) Penentuan kelompok-kelompok biaya yang homogeny (homogeneous cost poll)

Pada tahap ini biaya-biaya yang dikeluarkan dikelompokkan dengan biaya sejenis atau yang homogeny berikut tabel biaya kelompok sejenis

Tabel 3. Biaya Kelompok Sejenis

\begin{tabular}{r|rr|rr} 
Kelompok Aktivitas & \multicolumn{2}{|c|}{ Jenis Biaya } & \multicolumn{2}{c}{ Jumlah (Rp) } \\
\hline Mencanting & - Gas & Rp. & $200.000,-$ \\
\hline \multicolumn{2}{|c|}{ Malam } & Rp. & $3.400 .000,-$ \\
\hline \multicolumn{2}{r|}{ Pewarnaan } & Jumlah & Rp. & $3.600 .000,-$ \\
\hline \multicolumn{2}{r|}{ Jumlah } & Rp. & $14.500 .000,-$ \\
\hline Pemeliharaan & Pemeliharaan peralatan & Rp. & $129.000,-$ \\
\hline \multicolumn{2}{r|}{ Jumlah } & Rp. & $129.000,-$ \\
\hline Total & Rp. & $18.229 .000,-$
\end{tabular}

5) Penentuan tarif kelompok (pool rate)

Penentuan tarif kelompok overhead untuk penentuan harga pokok produksi Batik Tulis adalah sebagai berikut :

a) Aktivitas mencanting

Biaya yang termasuk kelompok biaya mencanting adalah pemakaian gas dan malam. Penentuan tarif kelompok berdasarkan jumlah bahan baku yang digunakan. Jumlah bahan baku yang digunakan selama bulan Juli 2018 sebesar 100 meter. Biaya tersebut dapat dirinci sebagai berikut:

Kelompok aktivitas mencanting $=\frac{\mathrm{Rp} 3.600 .000,-}{100 \mathrm{~m}}$

$$
=\operatorname{Rp} 36.000 / \mathrm{m}
$$

b) Aktivitas pewarnaan

Biaya yang termasuk pada kelompok biaya pewarnaan adalah biaya yang dikeluarkan untuk membeli bahan pewarna. Penentuan tarif kelompok berdasarkan jumlah bahan baku yang digunakan 
selama bulan Juli 2018. Jumlah bahan baku yang digunakan sebesar 1500 meter untuk pembuatan batik tulis dan batik cap.

$$
\begin{aligned}
\text { Kelompok aktivitas pewarnaan } & =\frac{\operatorname{Rp} 14.500 .000,-}{1500 \mathrm{~m}} \\
& =\operatorname{Rp} 9.667 / \mathrm{m}
\end{aligned}
$$

c) Aktivitas pemeliharaan

Biaya yang termasuk kelompok biaya pemeliharaan adalah biaya perawatan peralatan dalam pembuatan batik mulai dari proses pembuatan hingga siap untuk dijual. Penentuan tarif kelompok berdasarkan jam kerja langsung yaitu sebesar 208 (8 jam x 26 hari)

$$
\text { Kelompok aktivitas pemeliharaan } \quad=\frac{\mathrm{Rp} 129.000,-}{208 \mathrm{JKL}}
$$

$$
=\operatorname{Rp} 620 / \mathrm{JKL}
$$

\subsubsection{Tahap Kedua}

Biaya overhead pabrik (BOP) setiap kelompok aktivitas dilacak ke jenisjenis produk menggunakan tarif kelompok yang dikonsumsi setiap produk. Pembebanan BOP produk dihitung dengan rumus :

1) Aktivitas Mencanting

Aktivitas mencanting adalah proses pembuatan pola pada batik tulis dengan menggunakan canting yang dicelupkan ke malam panas kemudian di lukiskan mengikuti pola pada kain mori. Biaya yang termasuk kelompok biaya mencanting adalah pemakaian gas dan malam. Pengalokasian biaya ke cost driver berdasarkan pada jumlah bahan baku, karena jumlah bahan baku adalah pemicu terjadinya biaya tersebut. Jumlah bahan baku yang digunakan untuk pembuatan batik tulis sekitar 100 meter. Biaya yang digunakan untuk aktivitas pencantingan selama bulan Juli 2018 sebesar Rp 3.600.000,-Berikut alokasinya:

Tabel 4. Alokasi Biaya Aktivitas Mencanting

\begin{tabular}{c|c|c|c} 
Produk & Tarif Kelompok (Rp) & Unit Driver & Jumlah (Rp) \\
\hline Batik Tulis & Rp. 36.000,- & 100 & Rp. 3.600.000,-
\end{tabular}

2) Aktivitas Pewarnaan

Aktivitas pewarnaan adalah aktivitas pewarnaan kain dengan cara dicelup dan diberikan pewarna. Biaya yang termasuk kelompok pewarnaan adalah pemakaian bahan pewarna. Pengalokasian biaya ke cost driver berdasarkan jumlah pemakaian bahan baku batik tulis dan batik cap sebesar 100 meter, karena pemakaian bahan baku merupakan pemicu terjadinya biaya. Biaya yang digunakan untuk aktivitas pewarnaan selama bulan Juli 2018 adalah sebesar Rp 966.667,-. Berikut alokasi biayanya.

Tabel 5. Alokasi Biaya Aktivitas Pewarnaan

\begin{tabular}{c|c|c|c} 
Produk & Tarif Kelompok (Rp) & Unit Driver & Jumlah (Rp) \\
\hline Batik Tulis & Rp. 9.667,- & 100 & Rp. 966.667,-
\end{tabular}

3) Aktivitas Pemeliharaan

Aktivitas pemeliharaan adalah aktivitas yang berhubungan dengan pemeliharaan atau perawatan peralatan yang digunakan untuk proses produksi 
pengalokasian biaya ke cost driver berdasarkan pada jam kerja langsung. Karena jam kerja langsung adalah pemicu terjadinya biaya tersebut. Jumlah jam kerja langsung yang dianggarkan untuk pembuatan batik tulis sebesar Jam Kerja Langsung 208 jam (8 jam x 26 hari). Biaya yang digunakan dalam aktivitas pemeliharaan selama bulan Juli 2018 sebesar Rp 129.000,- . berikut pengalokasian biayanya:

Tabel 6. Alokasi Biaya Aktivitas Pemeliharaan

\begin{tabular}{c|c|c|c} 
Produk & Tarif Kelompok (Rp) & Unit Driver & Jumlah (Rp) \\
\hline Batik Tulis & Rp. 620,- & 208 & Rp. 129.000,-
\end{tabular}

Jumlah biaya overhead yang dialokasikan menggunkan sistem activity based costing dapat dirinci sebagai berikut :

Tabel 7. Biaya Overhead Yang Dialokasikan

\begin{tabular}{l|rr} 
Kelompok Biaya & \multicolumn{2}{|c}{ Jumlah $(\mathrm{Rp})$} \\
\hline Mencanting & Rp. & $3.600 .000,-$ \\
\hline Pewarnaan & Rp. & $966.667,-$ \\
\hline Pemeliharaan & Rp. & $129.000,-$ \\
\hline Jumlah & Rp. & $4.695 .667,-$
\end{tabular}

Sumber : Data primer yang diolah Juli 2018

Jumlah biaya overhead pabrik yang dialokasikan dengan sistem activity based costing sebesar Rp. 4.695.667,-

Selanjutnya dilakukan perhitungan harga pokok produksi dengan sistem activity based costing adalah sebagai berikut :

\begin{tabular}{|c|c|c|c|c|c|c|c|c|}
\hline Jumlah & BBB & & BTK & & BOP & & HPP & HPP/unit \\
\hline Unit (M) & $\mathrm{Rp}$ & $\%$ & $\mathrm{Rp}$ & $\%$ & $\mathrm{Rp}$ & $\%$ & & \\
\hline 100 & Rp. 2.200 .000 & 9 & Rp 18.800 .000 & 73 & Rp. 4.695 .667 & 18 & Rp.25.695.667,- & Rp. 256.957,- \\
\hline
\end{tabular}

\section{KESIMPULAN}

Berdasarkan penelitian dan pembahasanan penelitian ini maka dapat disimpulkan bahwa penentuan harga pokok produksi batik tulis pada Batik Tobal dengan perhitungan menggunakan sistem activity based costing hasilnya sebesar Rp. 25.695.667,- untuk jumlah unit yang diproduksi 100 meter jadi untuk harga pokok produksi batik tulis permeternya sebesar Rp. 256.957,-.

\section{SARAN}

Saran penelitian selanjutnya

1. Menggunakan metode yang lainnya serta membandingkan metode mana yang lebih optimal meningkatkan laba

2. Subjek penelitian dapat diperbanyak agar dapat di generalkan hasilnya, sehingga bermanfaat bagi Owner Usaha Batik Lainnya dalam menentukan Harga Pokok Produksi batik dan memperoleh keuntungan yang optimal. 


\section{DAFTAR PUSTAKA}

Blocher, Edward J., Kung H. Chen., and Thomas W. Lin, 2000 “ Cost Management a strategic Emphasis" (Terjemahan Susty Ambarriani) Jakarta : Salemba

Daljono, 2009. Akuntansi Biaya, edisi 3. Semarang : Badan Penerbit Universitas Diponegoro

Garrison, Ray H., Eric W. Noreen., 2000. Akuntansi Manajerial, Buku 1, Alih Bahasa A. Totok Bidisantoso, Salemba Empat, Jakarta

Hansen,Mowen. Heitger. 2012. Managerial Accounting The Cornerstone of Business Decision. 4th Edition. South-Western : Cengage Learning

Mulyadi. 2009. Akuntansi Biaya. Edisi ke-5 cetakan kesembilan, Penerbit UPP-STIM YKPN, Yogyakarta.

R.A Supriyono. 2002. “Akuntansi Manajemen”. Jakarta : Salemba Empat

Sujarweni. V Wiratna. 2015. "Akuntansi Biaya Teori \& penerapannya” Yogyakarta.: Pustaka Baru Press. 